\title{
Business Cycles Analysis in Cameroon: An Overview
}

\section{Mfouapon A and Sundjo F*}

Department of Economics, F.E.M.S, University of Bamenda, Bambili, Cameroon

*Corresponding author: Fabien Sundjo, Department of Economics, F.E.M.S, University of Bamenda, Bambili, Cameroon, Email: alas.mfouapon@yahoo.fr

\section{Research Article}

Volume 4 Issue 4

Received Date: July 07, 2021

Published Date: July 21, 2021

DOI: $10.23880 /$ jqhe-16000233

\section{Abstract}

This paper aims at conducting a thorough analysis of business cycles in Cameroon by statistically assessing their main characteristics. The analysis is carried out by considering the three dimensions of macroeconomic fluctuations. By assessing output volatility, light on the sensitivity of the economy to exogenous shocks as well as to endogenous sources of instability is shed. Likewise, analysing the co-movements of aggregate variables of interest helps in understanding the extent to which the observed fluctuations relate to other aggregates in the economy and hence, the main forces driving the dynamics of this economy. Eventually, more light could be shed on macroeconomic dynamics by analysing the timing and persistence of business cycles. Overall, such analysis is conducted using basic statistical tools commonly used in the empirical literature on business cycles. These are the standard deviation as a measure of volatility, cross-correlations as a means of analysing comovements and auto-correlations as measures of persistence. The main limitation in this study is the linear consideration of observed data. In fact, many macroeconomic and financial time-series that are used in quantitative macroeconomic models are subject to a number of regime-switching in reality. This fact needs to be taken into account in the subsequent research.

Keywords: Business Cycles; Developing Countries; Volatility; Persistence and Co-movement

\section{JEL: B23, B26, C82, E32}

\section{Introduction}

This paper aims at proposing an overall description of business cycles in Cameroon by statistically assessing their main characteristics. Unlike industrialized countries, little attention has been paid to the analysis of business cycles in developing countries. As argued by Agénor, et al. [1], there are at least two factors that may explain this: First, limitations in data quality and frequency could be a constraining factor in some cases. For instance, quarterly data on national accounts are available for only a handful of developing countries; and even when these are available, they are considered to be of significantly lower quality. Second, developing countries tend to be proned to sudden crises and marked gyrations in macroeconomic variables, hence making it difficult to discern any type of "cycle" or economic regularities. Thus, very helpful are the few available studies such as those by Agénor et al. [1], Rand, et al. [2], Neumeyer, et al. [3], Arguar, et al. [4]. In particular, Agénor, et al. [1] established a set of stylized facts for the business cycles of developing countries and this has become the benchmark upon which most subsequent studies compare their findings.

Based on a sample of twelve middle-income developing countries (Korea, Malaysia, Mexico, Morocco, Nigeria, the Philippines, Tunisia, Turkey, and Uruguay) for the period 1978:1-1995:4, Agénor, et al. [1] found significant differences between developing and industrialised countries with respect to business cycles. Their key findings are as follows: First, output volatility varies substantially across developing countries and is on average much higher than the level typically observed in industrialised countries. However, developing countries also show higher persistence in output fluctuations as compared to industrialised countries. 
Second, activity in industrialised countries, as measured by the output and world real interest rate, has a significantly positive influence on output in most developing countries. Third, government expenditures and the fiscal impulse appear to be counter-cyclical while there is no distinct pattern in government revenue which seems to be acyclical in some countries and significantly countercyclical in others. Fourth, there is evidence of procyclicality in real wages as is the case in developed countries. Fifth, while prices are widely documented as being countercyclical in the industrialized countries, there appears that there are no consistent relationships between either output and prices or output and inflation in developing countries. Sixth, contemporaneous correlations between money and output are positive, but not very strong, and this contrasts with the evidence from many industrialised countries. This also suggests that there is a need to examine the key roles that are often assigned to monetary policy in stabilization programs in developing countries. Furthermore, while the velocity of broad money is weakly procyclical, in most industrialized countries, it appears to be strongly countercyclical in developing countries. Seventh, there is no robust relationship between the trade balance and output. In the countries where this relation is procyclical, this "may indicate that fluctuations of industrial output are driven by export demand and that imports are not as sensitive to domestic demand fluctuations as they are in industrial countries" [1]. Furthermore, the terms of trade are strongly procyclical suggesting that much of the fluctuations in output in developing countries can be explained by terms of trade shocks, as has been suggested by Mendoza, et al. [5].

In the frame of this paper, a first attempt to document a wide range of regularities in macroeconomic fluctuations in Cameroon is provided as the main objective. This objective is achieved by considering the three dimensions of macroeconomic fluctuations:

$>$ Output volatility as an indicator of the sensitivity of the economy to exogenous shocks as well as to endogenous sources of instability.

$>$ The co-movements of aggregate variables of interest sheds light on the extent to which the observed fluctuations relate to other aggregates in the economy.

$>$ Also important is the assessment of how persistent do observed business cycles tend to be.

The analysis relies on three basic statistical tools commonly used in the empirical literature on business cycles. These are:

$>$ the standard deviation as a measure of volatility;

$>$ cross-correlations as a means of analysing comovements;

$>$ and auto-correlations as measures of persistence. Unfortunately, while the usual practice is to rely on quarterly data, the data available to us for Cameroon are of annual periodicity going from 1980 to 2017. This is unfortunate as this may be criticized on the grounds that the annual frequency would not allow one to fully capture short run dynamics of the economy. In addition, our results may be less straightforwardly comparable to those reported in other studies like Agénor, et al. [1] or Rand, et al. [2] for other countries. As the main contribution to the business cycles literature, the paper looks for the importance of commodity (oil and non-oil) price fluctuations in conducting business cycles in developing countries such as Cameroon for instance.

The rest of the paper is organized as follows. Section 2 briefly presents the data, the analysis as well as the empirical strategy. Section 3 discusses the main results. Section 4 concludes.

\section{Data and Empirical Setup}

We rely on annual data to analyse economic business cycle in Cameroon. These data are drawn from the International Financial Statistic (IFS), database of the International Monetary Fund (IMF), the central bank of central Africa states (CBCAS) as well as from the National Statistical Institute (NSI) of Cameroon (see appendix for more details).

The variables we use are: $g d p$ - output; inv-investment; $\pi$-inflation; $x$-exports; $m$-imports; $x n$-net exports; $c$-private consumption; $g$-government consumption; $b^{*}$ - external debt; rer-real exchange rate; ner-nominal exchange rate; tot-terms of trade; $M 2$-broad money; $c r$-private sector credit; $r$-real interest rate; $i$-nominal interest rate; $c p i$-consumer price index; $w$-real wages; $y^{*(U S)}-$ US-real GDP; $P_{o}^{*}-$ world oil price, $P_{w d}^{*}-$ world wood price; $r^{*}-$ real treasury bill rate.

Prior to empirical analysis, we first de-trend the natural logarithm of every variable using the Hodrick-Prescott (HP) filter.

\section{De-Trending: The Hodrick-Prescott Filter}

De-trending in business cycle studies helps to decompose all macroeconomic series into non-stationary (trend) and stationary (cyclical) components. Different procedures are used in the literature [6] to extract trends from the observed time series. These procedures are divided into two broad categories: 'statistical' methods, which assume that the trend and the cycle are unobservable but use different statistical assumptions to identify the two components, and 'economic' methods, where the choice of trend is dictated by an economic model, by the preferences of the researcher or by the question being asked. Since only trend and cycle 
are assumed to exist, all the procedures implicitly assume that either data have previously been seasonally adjusted or that the seasonal and the cyclical component of the series are lumped together and that irregular (high frequency) fluctuations are negligible. Throughout this paper, we denote the natural logarithm of the time series by $x_{t}$, its trend by $x_{t}^{g}$ and its cyclical component by $x_{t}^{c}$. In choosing a de-trending technique, most researchers appear to opt for 'economic methods' with either the Hodrick-Prescott (HP) filter [7] or the band-pass (BP) filter [8].

In the Real Business Cycle (RBC) literature the trend of a time series is not intrinsic to the data but is rather a representation of the preferences of the researcher and depends on the economic question being investigated. The popularity of the HP filter among applied macroeconomists results from its flexibility to accommodate these needs since the implied trend line resembles what an analyst would draw by hand through the plot of the data see, for example, Kydland, et al. [9]. The selection mechanism that economic theory imposes on the data via the HP filter can be justified using the statistical literature on curve fitting see, for instance, Wabha, et al. [10]. In this framework the HP filter optimally extracts a trend which is stochastic but moves smoothly over time and is uncorrelated with the cyclical component.

The HP filter is a linear filter designed to optimally extract a trend component, which changes smoothly over time, from an observed non-stationary time series. Assuming that the (de-seasonalized) time series $x_{t}$, can be decomposed into an additive cyclical component $x_{t}^{c}$ and a trend component $x_{t}^{g}$, extracting the trend component will yield a stationary cyclical component, which can be used by researchers to analyse business cycles:

$$
x_{t}=x_{t}^{c}+x_{t}^{g} \text { for } t=1, \ldots \ldots, T
$$

The standard HP filter [7] employs an adjustment rule whereby the trend component $x_{t}^{g}$, moves continuously and adjusts gradually. Formally, the trend component is extracted by solving the following minimization problem.

$$
\min _{\left\{x_{t}^{g}\right\}_{t=0}^{\infty}} \sum_{t=1}^{\infty}\left\{\left(x_{t}-x_{t}^{g}\right)^{2}+\left[\left(x_{t+1}^{g}-x_{t}^{g}\right)-\left(x_{t}^{g}-x_{t-1}^{g}\right)\right]^{2}\right\}
$$

The first term in the expression is the sum of squared deviations between the observed data and the trend, and is a measure of the goodness of fit of the trend to the original series. The objective is to select the trend component that minimizes the sum of squared deviations from the observed series, subject to the constraint that changes in $x_{t}^{g}$ vary gradually over time. The Lagrange multiplier $\lambda$ is a positive number that penalizes changes in the trend component. The larger the value of $\lambda$, the smoother is the resulting trend series.
The HP filter has been subject to various criticisms [11]. In particular, it has been argued that it removes potentially valuable information from the time series [12], and so, it may impact cyclical patterns of the data [13]. More important in our case is the choice of the value of $\lambda$. The usual practice in the literature is to set $\lambda$ to 1600 for quarterly time series, and 100 for annual time series. However, imposing this specific value (which was derived from an examination of the properties of US output data) for each series is somewhat arbitrary, and may reflect an overly stringent implicit assumption about the degree of persistence in $x_{-} t$.

\section{Volatility, Persistence, and Co-Movement}

Once the series have been detrended and hence, the cyclical components obtained, the statistical analysis of the resulting stationary data can be carried out. As mentioned earlier, the statistical analysis in this paper concentrates on volatility, persistence, and cross-correlations.

\section{- Volatility}

Volatility reports the magnitude of fluctuations of the variables of interest. Volatility is measured by the standard deviation of the variable while relative volatility is the ratio between the volatility of the variable of interest and the volatility of industrial production. A relative volatility of one implies that the variable has the same cyclical amplitude as the aggregate business cycle (as proxied by industrial production) while a relative volatility greater than one implies that the variable has greater cyclical amplitude than the aggregate business cycle.

\section{- Persistence}

Persistence can be broadly defined as the speed with which a variable returns to its baseline (or its previous level) after, say, a shock (for instance, a macroeconomic policy measure) or an "innovation". In other words, is said to be more inertial when it slowly converges (or returns) to its previous level after the occurrence of a stimulus. Persistence is thus inversely related to the concept of mean reversion.

Quantifying the response of $x_{t}$ to a shock is indeed important not only because it may allow one to assess the effectiveness of economic policy measures but also because it may show at what point it is more appropriate to act in order to overcome a harmful effect of a shock to $x_{t}$. By definition, quantifying the response $\mathrm{f} x_{t}$ to shocks implies evaluating the persistence of $x_{t}$.

The implication of that definition is that, the degree of persistence can be associated with both the speed with which $x_{t}$ responds to a shock and the length (permanent or temporary) of the shock effects. When the value is small, $x_{t}$ responds quickly to a shock and returns quickly to its trend. 
Conversely, when the value is high, the speed of adjustment is low, and $x_{t}$ will tend to converge more slowly to its baseline. Therefore, if the degree of persistence is small, a shock tends to have temporary effects and conversely if the degree of persistence is high, a shock tends do have more long-lasting effects.

The estimate of persistence at time is obtained via the use of autoregressive model as in Belbute, et al. [14]. A univariate AR $(\mathrm{k})$ process is characterized by the following expression:

$$
x_{t}=\alpha+\sum_{j=1}^{k} \beta_{j} x_{t-j}+\varepsilon_{t}
$$

Where is explained by a constant $\alpha$, by past values up to lag $k$, and by a number of other factors whose effect is captured by the random term $\varepsilon_{t}$.

The persistence of the cyclical component of a variable is measured by its autocorrelation function:

$$
r(k)=\frac{\sum_{t=k+1}^{T}\left(x_{t}-\bar{x}\right)\left(x_{t-k}-\bar{x}\right)}{\sum_{t=1}^{T}\left(x_{t}-\bar{x}\right)^{2}}
$$

Where $T$ is the sample size and $k$ is the number of lags. The significance of the persistence is validated using the LjungBox portmanteau $(Q)$ test for white noise. The Ljung-Box $Q$-statistic helps to decide if the null hypothesis which states that there is no auto-correlation up to order $k$ is accepted. Under this hypothesis, the Ljung-Box $Q$-statistic is given by:

$$
Q=T(T+2) \sum_{j=1}^{k} \frac{r_{j}^{2}}{T-j}
$$

and is asymptotically distributed as a $\chi^{2}$ with $\mathrm{k}$ degrees of freedom.

\section{- Cyclicality}

The degree of co-movement between two variables and is measured with their unconditional cross-correlation function.

$$
\begin{gathered}
r_{x y}(k)=\operatorname{Corr}\left(x_{t}, y_{t-k}\right)=\frac{\sum_{t=k+1}^{T}\left(x_{t}-\bar{x}\right)\left(y_{t-k}-\bar{y}\right)}{\sum_{t=1}^{T}\left(x_{t}-\bar{x}\right)^{2}} \\
k \in\{0, \pm 1, \pm 2, \ldots\}
\end{gathered}
$$

These correlations estimated for the stationary components of variables that have been detrended using the same filter. Assuming to be an indicator and the cyclical component of real GDP, $y$ is considered to be procyclical, acyclical or counter-cyclical depending on whether the contemporaneous correlation coefficient $r(0)$ is positive, zero, or negative, respectively.

Following Agenor, et al. [1], the indicator is considered to be strongly contemporaneously correlated if $0.26 \leq|r(0)|<1$ , weakly contemporaneously correlated with the cycle if $0 \leq|r(0)|<0.13$, and contemporaneously correlated if $0.13 \leq|r(0)|<0.26$. In addition, $y_{t}$ is said to lead the cycle by $k$ period(s) if $|r(k)|$ is maximum for a negative, to be synchronous if $|r(k)|$ is maximum for $k=0$, and to lag the cycle if $|r(k)|$ is maximum for a positive $k$.

\section{Results}

In this section, we describe the main features of business cycles in Cameroon through three dimensions: volatility, cross-correlation and persistence. The results are reported in Tables 1-3 below. However, two remarks are in order. First, whenever relevant, the variables of interest are measured in per capita terms. Second, all of the variables have been detrended using the HP filter with the smoothing parameter $\lambda$ set to 100 .

\section{Volatility}

We gauge the volatility and persistence of business cycle fluctuations by examining summary statistics for the stationary component of real GDP, components of aggregate demand and inflation. The second and third columns of Table 1 report the means and standard deviations of output growth rates and standard deviations of the cyclical components of output derived using the HP with $\lambda$ set at 100 . Output growth rates are measured as year differences of the log levels of output. The taking into account of the mineral-GDP in this study yields on the importance of the mining sector in the Cameroonian economy with an average share of 20 percent contribution to the GDP (African economic outlook, 2014, 2012).

\begin{tabular}{|c|c|c|c|c|c|c|c|}
\hline \multirow{2}{*}{\begin{tabular}{c} 
Output measure and filter \\
\cline { 5 - 8 }
\end{tabular}} & \multirow{2}{*}{ Mean (\%) } & \multirow{2}{*}{ St. dev (\%) } & \multicolumn{5}{|c|}{ Autocorrelations } \\
\cline { 5 - 8 } & & & Lag 1 & Lag 2 & Lag 3 & Lag 4 & Q(p-value) \\
\hline Aggregate GDP & & & & & & & \\
\hline Growth & 4.8 & 13.75 & 0.45 & 0.17 & 0 & -0.35 & $12.31(0.00)$ \\
\hline HP & & 8.21 & 0.13 & 0.03 & -0.13 & -0.29 & $07.01(0.00)$ \\
\hline
\end{tabular}




\section{Journal of Quality in Health care \& Economics}

\begin{tabular}{|c|c|c|c|c|c|c|c|}
\hline BP & & 5.48 & 0.34 & 0.34 & -0.25 & -0.38 & $04.17(0.01)$ \\
\hline Non-Commodity GDP & & & & & & & \\
\hline Growth & 4.2 & 5.82 & 0.59 & -0.63 & -0.23 & -0.37 & $08.47(0.00)$ \\
\hline HP & & 3.44 & 0.41 & -0.05 & -0.09 & -0.07 & $03.22(0.00)$ \\
\hline BP & & 1.37 & 0.89 & 0.47 & 0.13 & -0.17 & $05.36(0.00)$ \\
\hline Non-Commodity private GDP & & & & & & & \\
\hline Growth & & & & & & & \\
\hline HP & 5.7 & 9.31 & 0.29 & 0.14 & -0.02 & -0.26 & $09.78(0.01)$ \\
\hline BP & & 4.56 & 0.44 & 0.11 & -0.01 & -0.11 & $06.55(0.00)$ \\
\hline Commodity GDP & & 2.78 & 0.89 & 0.54 & 0.12 & 0 & $03.67(0.00)$ \\
\hline Growth & 4.2 & 24.78 & 0.22 & 0.13 & 0.07 & -0.28 & $07.49(0.00)$ \\
\hline HP & & 17.15 & 0.05 & 0.04 & -0.05 & -0.15 & $05.88(0.00)$ \\
\hline BP & & 9.24 & 0.75 & 0.33 & -0.08 & -0.31 & $07.31(0.04)$ \\
\hline
\end{tabular}

Source: Author's calculations based on data obtained from the IFS database and World Bank.

Mineral GDP: mineral contribution to the GDP; Non-Mineral GDP: Non-mineral contribution to the GDP; Non-Mineral private GDP: Non-mineral private contribution to the GDP.

Table 1: Summary statistics for output.

The results reported in this table show that the mean annual growth rates during the sample period are 4.8 for aggregate output, 4.2 for commodity output and 5.7 for non-commodity output. The volatility of growth rates as measured by standard deviations indicates that commodityGDP is the most unstable, followed by aggregate GDP, and non-commodity GDP being the least volatile. The same pattern, albeit to a lesser extent, emerges from the standard deviations of the filtered cyclical components of output.

In comparison with output volatility in the USA, it is clear that output in Cameroon is 2.5 times more volatile than it is in the USA. Loayza, et al. [15] document that output in developing economies is significantly more volatile than in industrialized economies and suggest that, the excessive volatility in developing economies may arise from three key sources: The first is that developing countries are subject to greater exogenous shocks. The second is that, developing economies may be subject to greater domestic shocks arising, for example, from policy mistakes. The third and final suggestion is that external shocks have greater effects on volatility because developing economies do not possess neither the financial markets necessary to diversify risks nor the ability to perform stabilising macroeconomic policies. The latter effect has significant implications for the welfare of an economy. Hnatkovska, et al. [16] document a significant negative relationship between economic growth and output volatility, which is exacerbated by underdeveloped financial markets and institutions. Thus, under these conditions, external shocks have a greater effect on volatility, hence inducing lower economic growth. In particular, it is estimated in Hnatkovska, et al. [16] that a one-standard-deviation increase in volatility would reduce the economy's growth rate by $1.3 \%$.

Table 2 reports measures of persistence and volatility in components of aggregate spending and inflation. Volatility is measured by the standard deviation as in Table 1 above, while the first order autocorrelation coefficient measures the persistence of series.

\begin{tabular}{|c|c|c|c|c|c|}
\hline Variables & $\sigma_{x}$ & $\sigma_{x} / \sigma_{y}$ & $\rho(1)$ & $Q$ & P-value \\
\hline$i n v:$ investment & 0.3480 & 2.531 & 0.327 & 4.748 & 0.00 \\
\hline$\pi:$ inflation & 0.6195 & 4.506 & 0.415 & 3.988 & 0.01 \\
\hline$c p i:$ consumer price index & 0.4225 & 3.073 & 0.473 & 5.180 & 0.00 \\
\hline$w:$ real wages & 0.0412 & 0.300 & 0.571 & 7.550 & 0.00 \\
\hline
\end{tabular}




\begin{tabular}{|c|c|c|c|c|c|c|}
\hline$M 2:$ broad money & 0.2018 & 1.468 & 0.524 & 6.358 & 0.02 \\
\hline$c r:$ private sector credit & 0.1790 & 1.302 & 0.393 & 3.576 & 0.03 \\
\hline$r:$ real interest rate & 0.2142 & 1.558 & 0.521 & 6.285 & 0.00 \\
\hline$i:$ nominal interest rate & 0.2525 & 1.837 & 0.490 & 5.559 & 0.09 \\
\hline$x:$ exports & 0.2094 & 1.523 & -0.653 & 9.874 & 0.03 \\
\hline$m:$ imports & 0.1552 & 1.129 & 0.751 & 13.060 & 0.14 \\
\hline$x n:$ net exports & 0.1816 & 1.321 & 0.721 & 12.037 & 0.00 \\
\hline$t o t:$ terms of trade & 0.2891 & 2.103 & 0.756 & 11.381 & 0.02 \\
\hline$c:$ private consumption & 0.1438 & 1.045 & 0.535 & 6.628 & 0.03 \\
\hline$g:$ government consumption & 0.1406 & 1.023 & 0.824 & 15.723 & 0.00 \\
\hline$r e r:$ real exchange rate & 0.1508 & 1.097 & 0.637 & 9.396 & 0.02 \\
\hline$n e r:$ nominal exchange rate & 0.1663 & 1.210 & 0.572 & 7.576 & 0.00 \\
\hline$y^{*(U S)}:$ US-real gdp & 0.3437 & 2.5 & 0.761 & 13.410 & 0.04 \\
\hline$P_{o}^{*}-$ world oil price & 0.3865 & 2.811 & 0.825 & 15.761 & 0.00 \\
\hline$r^{*}:$ real treasury bill rate & 0.1842 & 1.34 & 0.636 & 9.366 & 0.01 \\
\hline
\end{tabular}

Table 2: Components of aggregate spending, inflation, external conditions, and monetary and financial variables.

All data are at their annual frequency, deseasonalized by the HP filter. Absolute volatility is the standard deviation of each variable. Relative volatility is measured as the ratio of standard deviation of each variable and that of real GDP. Persistence is the AR (1) coefficient following subsection 2.2.2 above.

From table 2, it appears firstly that consumption is the less volatile of all the components of aggregate spending. However, it is more volatile than aggregate output, which contradicts the predictions of the Permanent Income and Life Cycle theories of consumption smoothing behaviour. Secondly, this fact also points to a lack of consumption smoothing over the course of the business cycle. Thus, large welfare gains may be possible through reductions in consumption volatility as is argued by Loayza, et al. [15].

Exports are more volatile than those reported in most studies $[2,17]$. Note that this instability may come from export earnings, export prices, and export quantities following Herrmann, et al. In the case of Cameroon, its exportations are concentrated in a narrow range of primary commodities (coffee, cocoa, wood, iron, diamond, bauxite, cobalt, etc.) and are destined to few markets. This implies that total export earnings are highly sensitive to changes in the prices and/ or quantities of the dominant export commodities, with the elasticity of earnings with respect to prices/quantities accounting for a significant share of the total sum. We can therefore argue that as the country diversifies its exports more and more, the elasticity of each export commodity will get smaller and smaller.

Government expenditures are more volatile. It is 1.023 times more volatile than output. Since government expenditure is importantly financed by tax revenues, it has been found that tax revenues in developing countries increase with the rise of commodity prices but that they are hurt by the volatility of these prices. More specifically, increased prices on imported commodities, lead to increased trade taxes and (to a smaller extent) consumption taxes being collected. Export prices are also positively associated with tax revenue collection, in large commodity-exporting countries, but the channel is through income taxes and nontax revenues rather than international trade taxes. However, the volatility of commodity prices, both of imported and exported commodities, is negatively affecting tax revenues. These findings point at the detrimental effect of commodity price volatility on developing countries public finance and highlight further the importance of finding ways to limit this price volatility and its adverse effects.

Previous analyses of business cycles Agénor, et al. [1]; Rand, et al. [2]; Mâle, et al. [17] suggest investment is highly volatile in developing countries. Here, results suggest that 
Cameroon is no exception as investment seems to be 2.531 times more volatile than output in this country.

Examination of absolute volatility also reveals that the real interest rate is more volatile in Cameroon than it is in the US economy. The volatility of the real interest rate is significantly greater than the volatility of output. As discussed in Agénor, et al. [1], this may be due to private sector credit having a significant influence on economic activities in countries where equity markets are weakly capitalised.

Examining the exchange rate volatility, the Cameroon economy displays significant exchange rate volatility. Both the nominal and real exchange rates are more volatile than output. This is a significant finding as one of the key features of international business cycles that has gained macroeconomists' interest is the volatility and persistence of real exchange rates. Flood, et al. [18] suggests that while the choice of exchange rate regimes affects the volatility of the exchange rate, the volatility of output is stable across regimes. In the Cameroon context, since the country has opted for a flexible exchange rate of its money (CFA franc) against the US-dollar, the Cameroon authorities will refrain from intervening in the foreign exchange market and will permit the currency to depreciate. This depreciation makes exports more competitive in world markets and thereby increases demand. Rising demand then stimulates activity in the export industries, cushioning the adverse impact of the terms-of-trade shock on output. However, where economies maintain a fixed exchange rate regime, exchange rates will be less volatile than output, and the authorities will require intervening in the foreign exchange market to keep the value of the two currencies in line. Thus, they will sustain the value of the local currency by purchasing it for dollars. This move will in turn drain the local currency out of the money market, reducing the amount of money and credit available for business investment and expansion. Because the authorities' actions are equivalent in their effects to a tightening of monetary policy, this response to the decline in export prices can lead to a costly contraction in output. This is consistent with the Asian experience for Hong Kong, Malaysia and Pakistan; all of which have held fixed, or pegged, exchange rates for significant durations.

\section{Persistence}

The persistence of business cycle fluctuations is assessed by examining the autocorrelations of the filtered series and the results are presented in Table 1, columns 4-7 and in Table 2 the fourth column of which reports the first autocorrelation. In the case of aggregate GDP and mining GDP, the autocorrelations from growth rates and HP-filtered series are weakly positive, but statistically insignificant. Autocorrelations for non-mineral GDP and non-mineral private GDP are relatively stronger and statistically significant indicating some persistence in the cyclical components. The autocorrelations from the BP-filtered series are the most strongly positive and statistically significant. One can therefore view Cameroon's non-mineral output as having short-term fluctuations that could be reasonably characterized as business cycles. These business cycles are characterized by low magnitude and low intensity compared to those of the developing countries studied by Agénor, et al. [1] and to the Central and Eastern European countries (CEE) and the EU countries investigated by Benczur, et al. [19]. The large gyrations in mineral GDP and aggregate GDP suggest that it will be difficult to discern any type of cycle or economic regularity on these aggregates. Moreover, the autocorrelations of their growth rates and HP-filtered series are statistically insignificant.

\section{Cyclicality}

The degrees of co-movement between real output and other variables are summarized in Table 3 below.

\begin{tabular}{|c|c|c|c|c|c|c|c|c|c|}
\hline Variables & $\mathbf{- 8}$ & $\mathbf{- 4}$ & $\mathbf{- 2}$ & $\mathbf{- 1}$ & $\mathbf{0}$ & $\mathbf{1}$ & $\mathbf{2}$ & $\mathbf{4}$ & $\mathbf{8}$ \\
\hline$i n v:$ investment & -0.37 & 0.03 & 0.51 & 0.63 & 0.62 & 0.67 & 0.54 & 0.35 & -0.24 \\
\hline$\pi:$ inflation & 0.11 & 0.15 & -0.20 & 0.19 & 0.27 & -0.34 & -0.23 & 0.06 & 0.17 \\
\hline$c p i$ : consumer price index & 0.16 & 0.19 & 0.07 & -0.11 & -0.21 & -0.24 & -0.19 & -0.01 & 0.13 \\
\hline$w$ : real wages & -0.24 & 0.23 & 0.11 & 0.32 & -0.25 & -0.18 & -0.22 & -0.19 & 0.00 \\
\hline$M 2:$ broad money & -0.04 & 0.55 & 0.71 & 0.67 & 0.42 & 0.19 & -0.04 & -0.53 & -0.37 \\
\hline$c r:$ private sector crdit & -0.31 & -0.42 & -0.06 & 0.11 & 0.18 & 0.27 & 0.31 & 0.37 & 0.03 \\
\hline$r:$ real interest rate & -0.17 & -015 & 0.28 & 0.43 & 0.46 & 0.38 & -0.22 & -0.19 & -0.31 \\
\hline$i:$ nominal interest rate & -0.07 & 0.11 & 0.21 & 0.22 & 0.20 & 0.05 & 0.01 & -0.18 & -0.18 \\
\hline
\end{tabular}




\begin{tabular}{|c|c|c|c|c|c|c|c|c|c|}
\hline$x:$ exports & 0.40 & 0.59 & -0.36 & 0.51 & 0.65 & 0.54 & 0.41 & -0.31 & 0.18 \\
\hline$m:$ imports & 0.14 & -0.05 & 0.32 & 0.40 & 0.59 & 0.36 & 0.28 & 0.03 & -0.17 \\
\hline$x n:$ net exports & 0.35 & 0.00 & -0.36 & -0.44 & -0.37 & -0.24 & -0.27 & -0.19 & -0.18 \\
\hline tot : terms of trade & -0.27 & -0.32 & 0.03 & 0.19 & 0.69 & 0.13 & 0.08 & -0.18 & -0.24 \\
\hline$c:$ private consumption & -0.22 & -0.20 & -0.19 & -0.06 & 0.24 & 0.38 & 0.53 & 0.42 & 0.00 \\
\hline$g:$ government consumption & 0.05 & -0.25 & -0.08 & -0.05 & 0.02 & 0.17 & 0.30 & 0.27 & -0.27 \\
\hline rer $:$ real exchange rate & -0.53 & -0.25 & -0.17 & -0.13 & -0.37 & -0.00 & 0.15 & 0.33 & 0.27 \\
\hline$n e r:$ nominal exchange rate & -0.45 & 0.37 & 0.61 & 0.43 & 0.57 & 0.39 & 0.22 & -0.33 & -0.19 \\
\hline$y^{*(U S)}:$ US-real gdp & 0.22 & -0.17 & -0.07 & -0.18 & -0.15 & -0.14 & -0.10 & -0.06 & -0.22 \\
\hline$P_{o}^{*}-$ world oil price & 0.59 & -0.26 & -0.78 & -0.54 & -0.74 & -0.26 & -0.06 & 0.20 & 0.17 \\
\hline$r^{*}:$ real treasury bill rate & 0.37 & 0.29 & 0.32 & 0.15 & -0.17 & -0.40 & -0.72 & -0.56 & -0.02 \\
\hline
\end{tabular}

Table 3: Cross-correlations: Real output, monetary and financial variables, components of aggregate demand and external conditions $\left(x_{t}, y_{t-k}\right)$.

All data are at their annual frequency, depersonalized by the band-pass filter. Absolute volatility is the standard deviation of each variable. Relative volatility is measured as the ratio of standard deviation of each variable and that of real GDP. Persistence is the AR (1) coefficient.

\section{- Correlations with External Conditions}

We first analyse correlations between real output and a set of variables representing the external environment. Real output is represented by real GDP, while the variables representing the external environment are US real GDP, world oil prices and the US real Treasury bill rate. This helps to give a specific accent to structural characteristics susceptible to make such an economy more vulnerable to external shocks such as the financial shock, the terms of trade shock, the export demand shock, the foreign inflation shock, the foreign commodity price shock, the oil price shock, the price of imports shock, and the foreign output shock. These shocks may be introduced into various structural equations in a DSGE model.

The contemporaneous correlation function indicates a negative and weak association between the US-GDP and the Cameroon real-GDP. This weak and countercyclical relationship is not surprising because Cameroon has weak trade links with the US. Agenor, et al. [1] also found that Morocco's, Nigeria's and Turkey's cycles are weakly and negatively related to the US cycle.

Second, we note that the world business cycle conditions could also influence fluctuations in a developing country through changes in real interest rates. In particular, Agénor, et al. [1] suggest that the relationship with the world real interest rate could be important because it is likely to affect economic activity in developing countries by both affecting domestic interest rates and by reflecting credit conditions in international capital markets. However, the results show that the contemporaneous correlation is weakly negative, suggesting that US real interest rates do not influence output in Cameroon.

A further channel through which world events could affect macroeconomic fluctuations is that of changes in oil prices. As expected, the results for world oil prices indicate a strong negative contemporaneous correlation. Since oil is an important input in the production process, an increase in its price is expected to raise production costs and dampen economic activity.

\section{- Components of Aggregate Demand}

Correlation coefficients between real output and components of aggregate spending are reported in column 4 .

- Household Consumption: The contemporaneous correlation between consumption and real GDP is positive, suggesting that private consumption in Cameroon is procyclical. The magnitude of the correlation functions seems to be smaller than those found in industrial and other developing countries as reported by Rand, et al. [2]; Mâle, et al. [17].

- Government Consumption: The Government plays a central role in the country as it is the main link between the export stability (commodity) and the rest of the economy. The Government levies royalties and tax 
revenues from the oil and mineral sector and channels the funds to other sectors through budgetary allocations. Cross correlations indicate weakly procyclical Government consumption. However, this does not necessarily signal any efficacy of the fiscal policy since Government consumption does not lead the cycle. This result is similar to those reported by Alpher, et al. [20] for Mexico and Turkey. Benczur, et al. [19] also found similar relationships for five out of twelve CEE countries, namely Croatia, Latvia, Lithuania, Poland and Slovakia. Other studies that found no clear cyclical pattern include Fiorito, et al. [21] for G-7 countries. Fiorito, et al. [21] argue that the relationship between Government consumption and output depends on a variety of factors, such as military expenditures in the total budget, the existence of stabilization programmes and the evolution of institutions.

- Investment: Investment is strongly procyclical and close to being synchronous. In fact, this is the component of aggregate spending most strongly associated with output. This is consistent with evidence from other studies reported in the literature [19].

- Net exports: Particularly, the procyclicality of the trade balance can be explained by the strong positive relationship between the business cycle and exports and the acyclicality of imports, which in combination will result in a positive trade balance during expansions and a negative trade balance during recessions. This contrasts with developed countries where expansionary business cycle phases result in an increased demand for imports and thus a negative trade balance. The close relationship between exports and the business cycle in these countries may extend from the implementation of export-led or outward-looking development strategies. According to table 3 the contemporaneous correlation coefficient between net exports and GDP is negative. This is consistent with much of the empirical literature $[4,22,19,23]$. Backus, et al. [22] contend that this counter-cyclicality arises because countries borrow from international capital markets.

- Imports: As expected, and in line with the experience of other countries $[1,2,17]$, imports are strongly procyclical. The phase shifts show that imports lead activity production. As an import-dependent economy the strong pro-cyclicality of imports in the case of Cameroon could mean that, imported inputs play an important role in Cameroon output fluctuations. This result may be exploited to introduce in a DSGE model for Cameroon a firm that import and distribute different varieties of foreign goods in the domestic market.

- Exports: Exports are positively correlated with real GDP, suggesting a strong pro-cyclicality with the business cycle. As an export-dependent economy, this could mean that export and more precisely, export commodities play an important role in Cameroon output fluctuations. Once again, this result may be exploited to introduce in the DSGE model for Cameroon a firm that produces a commodity good which is completely exported abroad, and also a firm that produces exportable goods that are consumed domestically.

- Terms of trade: It appears from table 3 that terms of trade are strongly pro-cyclical in Cameroon. This result is similar to the findings of both Agénor, et al. [1] Rand, et al. [2]. Agénor, et al. [1] suggest that, under the assumption that developing economies are too small to affect world prices, the pro-cyclical relationship may reflect demand shifts that yield simultaneous increases in world prices and demand for the country's exports. As such, both the economy's terms of trade and output would increase.

\section{Correlations with Monetary and Financial Variables}

Correlation coefficients between real output, monetary and financial variables are consistent with the evidence from other countries.

- Money: The views on whether monetary aggregates influence output in industrial countries are varied. However, many authors King, et al. [24] agree that the monetary mechanism could still play an important stabilizing role in middle income countries. The correlations between real GDP and both definitions of money, M1 and M2, show that money is highly cyclical and rather leading or synchronous. These results are consistent with those reported in Backus, et al. [22] using data for industrial countries and suggest that monetary policy could play an important role in short-term output fluctuation. However, this relationship may simply be reflective of the endogenous response of money to output fluctuations that are driven by non-monetary shocks as suggested by King, et al. [25].

- Private sector credit: Another monetary variable which has been found by Agénor, et al. [1] and Rand, et al. [2] to have an important influence on the business cycle in some developing countries is the real domestic private sector credit. Since equity markets are weakly capitalised in developing countries relative to industrialised countries, domestic private sector credit is thought to fulfil an important role in determining investment and hence economic activity in these countries. To examine whether credit influences output and vice versa, it is necessary to examine whether credit leads or lags the business cycle. For the majority of countries credit lags the business cycle, thus suggesting that it is fluctuations in output that influence credit. The contemporaneous correlation between output and credit in the case of 
Cameroon is weakly positive suggesting that credit is procyclical. However, the phase shifts do not show any clear and interpretable pattern between the two variables.

- Consumer price index and inflation: Next we turn to the correlations between prices and output. A substantial body of literature documents the countercyclical behaviour of prices in industrialised countries. It provides support for supply-driven models of the business cycle [20]. However, Chadha, et al. [26] argue that the appropriate correlation to discriminate between demand-driven and supply-driven models of the business cycle is between inflation and cyclical output. We therefore examined the cyclical behaviour of both the price level and inflation rate. The contemporaneous correlation between output and consumer price level is negative, indicating countercyclical variation of the price level. Similarly, the inflation rate is countercyclical and synchronous, indicating that appropriate models for Cameroon would be supply-driven as opposed to the more conventional demand-driven models. Similar findings are reported by Alper, et al. [20] for Mexico and Turkey.

- Real wages: The correlation between output and real wages shows much more consistency. In the case of Cameroon, the contemporaneous correlation is positive suggesting procyclical real wages. As discussed in Agénor, et al. [1], the identification of whether real wages are procyclical or countercyclical has important implications for the choice of theoretical models to represent developing countries business cycles.

- Nominaleffective exchangerate:Thecontemporaneous correlation indicates that nominal exchange rate is strongly procyclical and almost synchronous. This exchange rate behaviour could be explained by the high import-dependence of economic activities in Cameroon. A currency appreciation lowers the prices of imported inputs which may in turn stimulate production, especially where most of the output is for domestic consumption.

- Real exchange rate: The real effective exchange rate is weakly countercyclical with a contemporaneous correlation coefficient equal to -0.37 . The weak relationship between the exchange rate and the rest of the economy is well documented in the literature, and is known as the exchange rate disconnect puzzle following Obstfeld, et al. [27]. Thus, it is unlikely that there will be a clear pattern of correlations between output and exchange rates for a given sample of developing countries. However, for completeness, this relationship is considered [28-31].

- Nominal and real interest rates: when considering the impact of monetary policy on business cycles, it is also necessary to examine the relationship between output and interest rates. Most theoretical models suggest that interest rates are not key determinants of business cycles fluctuations. At the empirical level, the link between interest rates and business cycles is not clear. Neumeyer, et al. [3] found real interest rates to be mildly procyclical in developed countries and countercyclical in developing countries. This is based on results for Argentina, Brazil, Korea, Mexico, and the Philippines. Similarly, Uribe, et al. found real interest rates to be countercyclical in five developing economies: Argentina, Brazil, Ecuador, Mexico and Peru. Theoretically, because firms have to pay for factors of production before production takes place, working capital needs to make labour demand sensitive to interest rates fluctuations [32-37]. When interest rates increase, working capital becomes more expensive and firms tend to reduce their demand for labour. Correlations reported in Table 3 indicate that both nominal and real interest rates are procyclical, with the latter being strongly so and coincidental [38]. The positive and synchronous correlation between output and real interest rates can be explained by the dominance of non-mineral output, by the financial services and the contribution of interest income to banks profits 39]. That is, an increase in interest rates increases the interest income of the financial sector, especially commercial banks, because they hold central bank certificates. Since financial services account for a large proportion of non-mineral output, this shows up as an increase in economic activity $[40,41]$.

\section{Conclusion}

In this paper, the main characteristics of business cycles in Cameroon are statistically highlighted. Such analysis has been conducted using basic statistical tools commonly used in the empirical literature on business cycles: the standard deviations as a measure of volatility, cross-correlations as a means of analysing co-movements and auto-correlations as measures of persistence. While part of the results of this study are in line with those reported for other developing countries, the other part is novel as it points to a variety of aspects that seem to be specific to the Cameroon economy. The main limitation in this study has been the linear consideration of observed data. In fact many macroeconomic and financial time-series that are used in quantitative macroeconomic models are subject to a number of regimeswitching in reality. This fact needs to be taken into account in the subsequent research.

\section{Compliance with Ethical Standards}

Conflict of Interest: The authors declare that he has no conflict of interest.

Ethical Approval: This study does not contain any studies with human participants or animals performed by the author. 


\section{References}

1. Agénor P (2000) Macroeconomic Fluctuations in Developing Countries: Some Stylized Facts. World Bank Economic Review, World Bank Group 14: 251-285.

2. Rand J, Tarp F (2002) Business Cycles in Developing Countries: Are They Different? World Development 30(12): 2071-2088.

3. Neumeyer PA, Perri F (2005) Business Cycles in Emerging Economies: The Role of Interest Rates. Journal of Monetary Economics 52: 345-380.

4. Aguiar M, Gopinath G (2007) Emerging Market Business Cycles: The Cycle Is the Trend. Journal of Political Economy, University of Chicago Press 115: 69-102.

5. Mendoza EG (1995) The terms of Trade, the Real Exchange Rate, and Economic Fluctuations. International Economics Reviews 36: 101-137.

6. Canova F (1998) Detrending and Business Cycle Facts. Journal of Monetary Economics 41: 475-512.

7. Hodrick RJ, Prescott EC (1997) Postwar U.S. Business Cycles: An Empirical Investigation. Journal of Money, Credit and Banking 29(1): 1-16.

8. Baxter M, King RG (1999) Measuring Business Cycles: Approximate Band-Pass Filters for Economic Time Series. Review of Economics and Statistics 81(4): 575593.

9. Kydland F, Prescott F (1990) Business Cycles: Real Facts and Monetary Myth. Quaterly Review, Federal Reserv Bank of Minneapolis, Spring 14: 3-18.

10. Wabha G (1980) Improper prior, spline smoothing and the problem of guarding against model errors in regression. Journal of the Royal Statistical Society Ser B 40(3): 364-372.

11. Stadler GW (1994) Real Business Cycles. Journal of Economic Literature 27: 1768-1769.

12. King R, Rebelo S (1993) Low filtering and the business cycles. Journal of Economic Dynamics and Control 17: 207-231.

13. Cogley T, Nason JM (1995) Output Dynamics in RealBusiness-Cycle Models. American Economic Review 85(3): 492-511.

14. Belbute J, Caleiro A (2013) Cross Country Evidence on Consumption Persistence. Int J Latest Trends Fin Eco Sci 3: 2.
15. Loayza N, Rancière R, Servén L, Ventura J (2007) Macroeconomic Volatility and Welfare in Developing Countries: An Introduction. The World Bank Economic Review 21(3): 343-357.

16. Hnatkovska V, Loayza N (2005) Volatility and Growth. Managing Economic Volatility and Crises. In: Aizenmann J, Pinto B, et al. (Eds.), Cambridge University Press, Cambridge, United Kingdom.

17. Mâle R (2010) Developing Country Business Cycles: Revisiting the Stylised Fact. School of Economic and Finance, Working Paper $\mathrm{N}^{\circ}$ pp: 664.

18. Flood R, Rose A (1995) Fixing Exchange Rates: A Virtual Quest for Fundamentals. Journal of Monetary Economics 36: 3-37.

19. Benczur P, Ratfai A (2010) Economic fluctuations in central and eastern Europe: The facts. Applied Economics 42(25): 3279-3292.

20. Alper CE (2003) Stylized facts of business cycles, excess volatitily and capital flows: Evidence from Mexico and Turkey. Russian and East European Finance and Trade 38: $22-54$

21. Fiorito R, Kollintzas T (1994) Stylized facts of business cycles in the G7 from real business cycle perspective. European Economic Review 38(2): 235-269.

22. Backus DK, Kehoe PJ (1992) International Evidence on the Historical Properties of Business Cycles. American Economic Review 82: 864-888.

23. Raffo R (2008) Net Export, Consumption Volatility, and International Business Cycle Models," Journal of International Economics 75: 14-29.

24. King R, Plosser C (1984) Money, Credit, and Prices in a Real Business Cycle. American Economic Review 74: 363-380.

25. King RG, Plosser CI (1994) Real business cycles and the test of the Adelmans. Journal of Monetary Economics 33(2): 405-438.

26. Chadha B, Prasad ES (1994) Are prices counter-cyclical? Evidence from the G7. Journal of Monetary Economics 34: 239-257.

27. Obstfeld M, Rogoff K (2000) New Directions for Stochastic Open Economy Model. Journal of International Economics 50: 117-153.

28. Blanchard 0, Gali J (2005) Real Wages Rigidities and New Keynesian Models. Massachusetts Institute of 
Technology, Department of Economics Working Paper 05-28.

29. Canova F (2007) Methods for Applied Macroeconomic Research. Princeton, NJ: Princeton University Press.

30. Coogley $T$ (2001) Estimating and testing rational expectations models when the trend specification is uncertain. Journal of Economic Dynamics and Control 25: 1485 .

31. Coogley TF (1995) Frontiers of Business Cycle research. Princeton: Princeton University Press.

32. Curdia V, Reis R (2011) Correlated Disturbances and U.S. Business Cycles. Department of Economics, Columbia University, pp: 1-58.

33. Erceg C, Henderson D, Levin A (2000) Optimal Monetary Policy with Staggered Wage and Prices Contracts. Journal of Monetary Economics 46: 281-313.

34. Tiryaki F, Gisele (2008) The Informal Economy and Business Cycles. Journal of Applied Economics 11(1): 91-117.
35. Hall GJ (1996) Overtime, Effort, and the Propagation of Business Cycle Shocks. Journal of Monetary Economics 38(1): 139-160.

36. Hansen G (1985) Indivisible Labor and the Business Cycle. Journal of Monetary Economics 16(3): 309-328.

37. Hendry DF (1995) Econometrics and Business Cycle Empirics. The Economic Journal 105: 1622-1636.

38. King R (1991) Value and Capital in the Equilibrium Business Cycle Program in Lionel Mckenzie and Stephano Zamagni, Value and Capital Fifty years Later, Macmillan (London).

39. Koreshkova T (2006) A Quantitative Analysis of In.ation as a Tax on the Underground Economy. Journal of Monetary Economy pp: 773-796.

40. Kydland FE, Prescott F (1982) Time to Build and the Aggregate Fluctuation. Econometrica 50: 1345-1370.

41. Rudebusch G (1992) Trends and random walks in macroeconomic time series. A reexamination. International Economic Review 33: 661. 